\title{
Cosmografía y corografía de Bogotá, siglos XVI Y XX1
}

\author{
Monika Therrien*
}

La cosmografía del siglo XVl

Es invariable el acuerdo que existe entre los autores sobre lo que representó para España el descubrimiento del Nuevo Mundo, particularmente el desarrollo científico que esto implicó. Con el fin de entender este continente y para controlar los nuevos dominios, uno de los cargos que tomó relevancia dentro de la estructura burocrática imperial y que fue instaurado por la monarquía fue el de Cosmógrafo, considerado como el más preparado para responder a la pregunta "¿qué son estas tierras descubiertas? y ¿dónde están ubicadas?” (Portuondo, 2009, p. 21). Titulado en sus inicios como Cosmógrafo y Cronista Mayor, posteriormente, este cargo terminó por dividirse y con ello se separaron las funciones de localizar y de describir los nuevos territorios.

Durante el siglo XVl y principios del siglo XVIl, el conocimiento de los cosmógrafos se sostuvo básicamente en la técnica dentro de la tradición renacentista española y tuvo como fundamento el corpus legado desde la antigüedad por Ptolomeo, más específicamente en su obra de Geografía, que las nuevas interpretaciones sobre el uso del texto indican que fue consultado a la manera de un manual, como un autor que guía al lector por los pasos necesarios para elaborar un mapa del oikoumené o "las partes conocidas del mundo" (Portuondo, 2009, p. 23). En esta obra, Ptolomeo señala las diferencias entre la geografía y la corografía: la primera abarcaba el mundo como una entidad continua y tenía que observar de manera amplia y general, basándose para ello en principios matemáticos ${ }^{1}$ aplicados a las dimensiones del espacio y del tiempo, mientras que la segunda implicaba el registro, hasta el más mínimo detalle de lo observado. Así, la geografía para Ptolomeo comprendía generar un texto complementario al mapa. El mapa se concentraba en el foco de la mirada al territorio, mientras el texto se convertía en una descripción auxiliar de las regiones y de la historia natural, de las plantas y animales y de las acciones de sus gentes en el mundo natural.

No obstante, con anterioridad a la reintroducción de la obra de Ptolomeo, en el pensamiento renacentista europeo también tuvieron cabida dos autores bastante reconocidos pero con aproximaciones epistemológicas contrarias frente a las descripciones: Strabo (muy popular en España), que apela a un estilo narrativo en prosa para detallar de manera verbal, más que cartográficamente la representación de un lugar y de sus habitantes, y Pomponio Mela (favorecido por el ámbito de las universidades), que se inclinó por una narrativa a la manera de diario de un viajero surcando por itinerarios geográficos que lo conducian de una región a otra.

Es así como en el renacimiento esta tradición narrativa humanista hizo que la cosmografía incluyera el relato histórico (Mignolo, 1995)², los registros etnográficos y la historia natural como parte del reconocimiento geográfico de un territorio, la cual se mantuvo y coexistió con la epistemología matemática de Ptolomeo hasta finales del siglo XVI, cuando en España la cosmografía fue escindida de la crónica.

\footnotetext{
* Cómo citar este artículo: * Therrien, M. (2013). Cosmografía y corografía de Bogotá, siglos XVI Y XXI. En Apuntes 26 (1):
} 


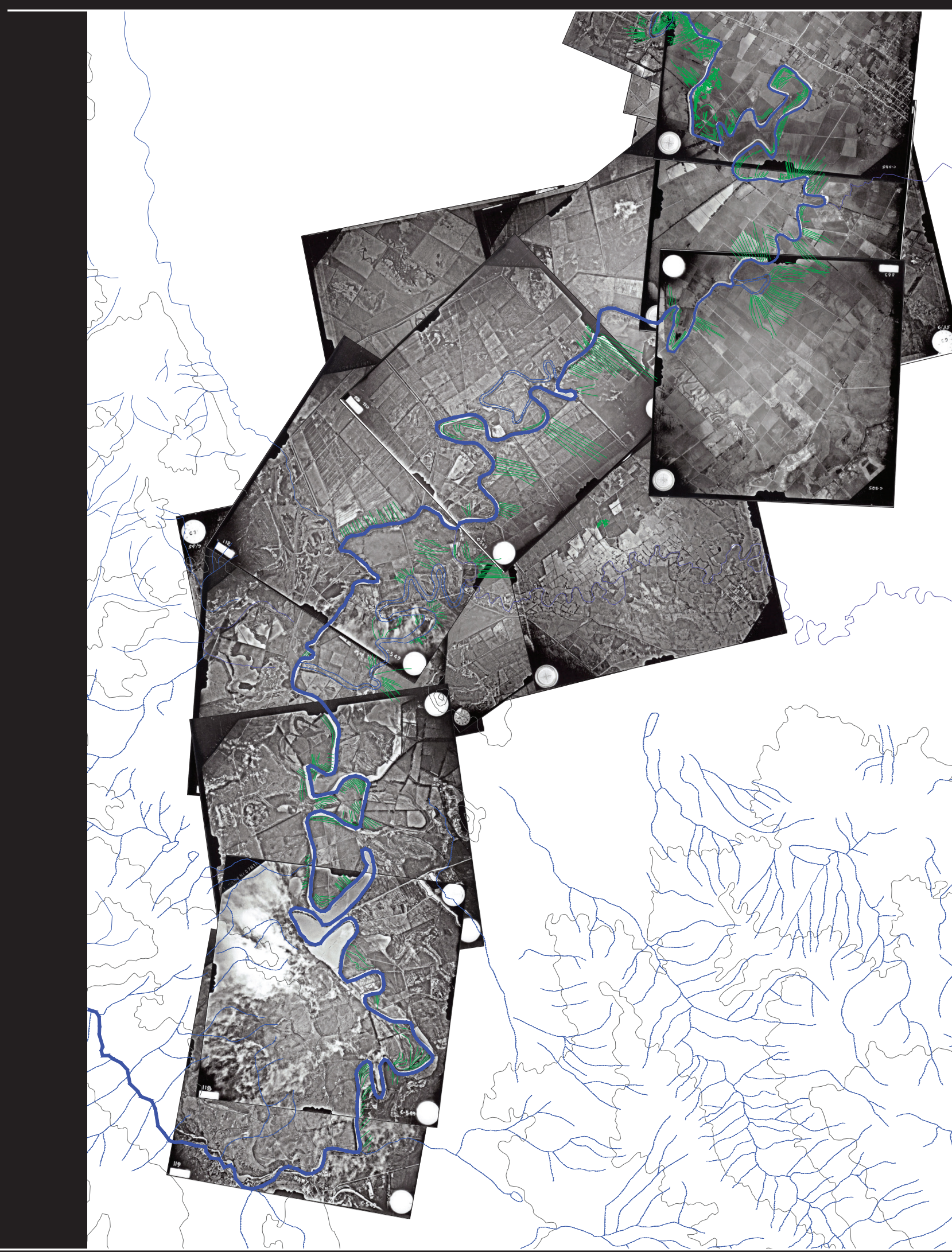




\title{
Cosmografía y corografía de Bogotá, siglos XVI Y XXI
}

\author{
Cosmography and Chorography of Bogotá, 16th and 17th Centuries \\ Cosmografia e corografia de Bogotá, XVI e XXl siglos
}

\section{Monika Therrien}

mtherrien@javeriana.edu.co

Antrópologa de la Universidad de los Andes, especialista en arqueología del Centre de Recherche Archéologique du Finistère (Francia). Magíster en Historia de la Universidad Nacional de Colombia y candidata a doctorado en Arquitectura de la Universidad Nacional de Colombia. Sus áreas de investigación son la arqueología histórica e industrial, la cultura material y el patrimonio cultural inmaterial. Actualmente su interés gira en torno al desarrollo de metodologías interdisciplinarias y participativas para la construcción de conocimiento abierto.

Resumen

La expansión imperial de los reinos europeos por el mundo, iniciada en el siglo XV, potenció el uso de la cartografía como un instrumento esencial para conocer y dominar los continentes donde ya habían incursionado y más aún, en los nuevos territorios por explorar. Con este propósito, a finales del siglo XVI la Corona Española reintrodujo la cosmografía como campo de conocimiento aplicado a los continentes de América y de Oceanía y desarrolló los instrumentos para el reconocimiento geográfico y corográfico de las tierras que fueron reclamadas en nombre del Rey. La cosmografía naturalizó unas formas de describir las nuevas colonias y a sus habitantes además de formas de producir, leer y usar los mapas, como representación de los logros e ideales de las políticas imperiales, concernientes al ordenamiento del territorio y a dar cuenta de la implementación de las normas reales. El artículo introduce algunos aspectos relevantes de la configuración del cargo de Cosmógrafo-Cronista Mayor y de los instrumentos que generaron una cosmografía y cartografía normativa y una reflexión sobre cómo crear una corografía y cartografía practicada basada ya no en la mirada oficial sino en una aproximación interdisciplinaria para entender los espacios donde confluyeron, coexistieron y se desenvolvieron los individuos de procedencias distintas, más específicamente en Santafé y Bogotá.

Palabras clave: Cosmografía, corografía, cronistas, cartografía practicada, Bogotá

Descriptores: Cosmografía-Historia- Bogotá, geografía histórica, historiografía, descubrimientos geográficos, ordenamiento territorial- Bogotá (Colombia)

Abstract

The imperial expansion of European kingdoms throughout the world, which began in the fifteenth century, increased the use of mapping as an essential tool to understand and master the continents where they had penetrated and specially in the new territories they aimed to explore. To this end, in the late sixteenth century the Spanish Crown reintroduced cosmography as a field of knowledge applied to the continents of America and Oceania, and developed instruments for the chorographic and geographical recognition of the territories claimed on behalf of the King. Cosmography naturalized ways to describe the new colonies and its habitants as well as ways to produce, read and use maps as a representation of the achievements and ideals of imperial policies, concerning land management and to report the implementation of the actual rules. The paper introduces some relevant aspects of the Mayor Chronicler Cosmograph post and of the instruments that generated a cosmography and a normative cartography, and a reflection on how to create a chorography and practiced cartography, based not in the official look but in an interdisciplinary approximation to understand the spaces where individuals from different backgrounds, specifically in Santa Fe and Bogota, converged, coexisted and developped.

Keywords: Cosmography, chorography, chroniclers, practiced cartography, Bogotá

Artículo de investigación

Este artículo hace parte del proyecto de investigación $y$ tesis doctoral del Doctorado en Arquitectura "Corografía de Santafé de Bogotá y su entorno inmediato: Arqueología de la conformación espacial de la ciudad hasta 1639", Facultad de Artes, Universidad Nacional de Colombia, financiado por Colciencias - Fundación Erigaie.
Keywords plus: Cosmography-History-Bogotá, historical geography, historiography, geographical discoveries, land-Bogotá (Colombia)

\section{Resumo}

A expansão imperial dos reinos europeus em todo o mundo, começou no século XV, aumentou o uso de mapeamento como uma ferramenta essencial para entender e dominar os continentes onde tinham penetrado e, além disso, nos novos territórios a explorar. Para este fim, no final do século cosmografia Coroa espanhola XVI reintroduziu como um campo de conhecimento aplicado para os continentes da América e Oceania, e instrumentos desenvolvidos para chorographic reconhecimento geográfico e terras que foram reivindicados em nome do rei. Os naturalizados algumas maneiras cosmografia para descrever as novas colônias e habitats, bem como maneiras de produzir, ler e usar mapas como uma representação das conquistas e ideais da política imperial, sobre a gestão das terras e relatar a implementação do regras reais. 0 artigo apresenta alguns aspectos relevantes do cenário-Cronista Cosmógrafo por prefeito e instrumentos que geraram a cosmografia e regras de mapeamento e uma reflexão sobre como criar um mapeamento corografia e praticada, com base não na aparência oficial, mas uma aproximação disciplinas para compreender os espaços onde convergiram, coexistiram e indivíduos desembrulhou diferentes origens, especificamente em Santa Fé e Bogotá.

Palavras-chave: Cosmografia, corografia, repórteres, cartografia praticado, Bogotá

Palavras-chave descritores: Cosmografia-História-Bogotá, geografia histórica, historiografia, as descobertas geográficas, terra-Bogotá (Colômbia)

doi:10.11144/Javeriana.APC26-1.ccbs

* Los descriptores y keywords plus están normalizados por la Biblioteca General de la Pontificia Universidad Javeriana. 
En este escenario irrumpe la necesidad de incorporar el Nuevo Mundo a la cosmografía universal, lo que requirió apelar a "nuevas metodologías que facilitaran la recolección de información de todos los rincones del mundo, proveer un conjunto de principios interpretativos que permitieran organizar de manera eficiente la vasta documentación y articular esta información de manera que fuera comprensible" (Portuondo, 2009: 63). Los Cuestionarios de Relación ${ }^{3}$ se convirtieron en el principal instrumento del cosmógrafo para llevar a cabo tal tarea, pues con estos fueron recolectados los testimonios y experiencias personales o directas de los europeos en el continente americano (Solano, 1988). Sin embargo, en un escenario donde se disputaba la dudosa hegemonía imperial española sobre buena parte del globo (y Portugal la otra), bajo un regimen colonialista en entredicho por el drástico descenso demográfico de la población nativa y los continuos maltratos a esta, las relaciones y las consecuentes compilaciones efectuadas por el cosmógrafo-cronista serían censuradas o controvertidas en la mayoría de los casos.

Alonso de Santa Cruz es a quien se le atribuye el haber brindado las pautas al Consejo de Indias para que el cargo de cosmógrafocronista se institucionalizara, y haber planteado los lineamientos a seguir para el diseño de los cuestionarios que servirían de guía a la labor del cosmógrafo en su descripción y localización de las tierras recién descubiertas. La información recogida bajo el cuestionario elaborado por Alonso de Santa Cruz en 1546, y que consistía de 17 preguntas, se refería a la toponimia original y a los nuevos nombres dados por los españoles, a los hitos geográficos más importantes, a minerales y metales que pudieran ser explotados, sobre la fauna, la flora (usos culinarios o medicinales), la ubicación de sitios, hitos y áreas vecinas, de los pueblos, sus costumbres, sus creencias, su religión y la historia de sus gobernantes, entre otras preguntas (Millán, 2001).

A pesar de estos aportes, solo tras la muerte de Santa Cruz, ocurrida en 1569, se creó el cargo de Cosmógrafo-Cronista Mayor, como resultado de un proyecto de reestructuración en el flujo de información que servía de insumo para el funcionamiento del Consejo de Indias. El rey Felipe 11 nombra a Juan de Ovando para efectuar la visita al Consejo con este propósito. Ovando detecta dos enormes fallas: la falta de una identificación

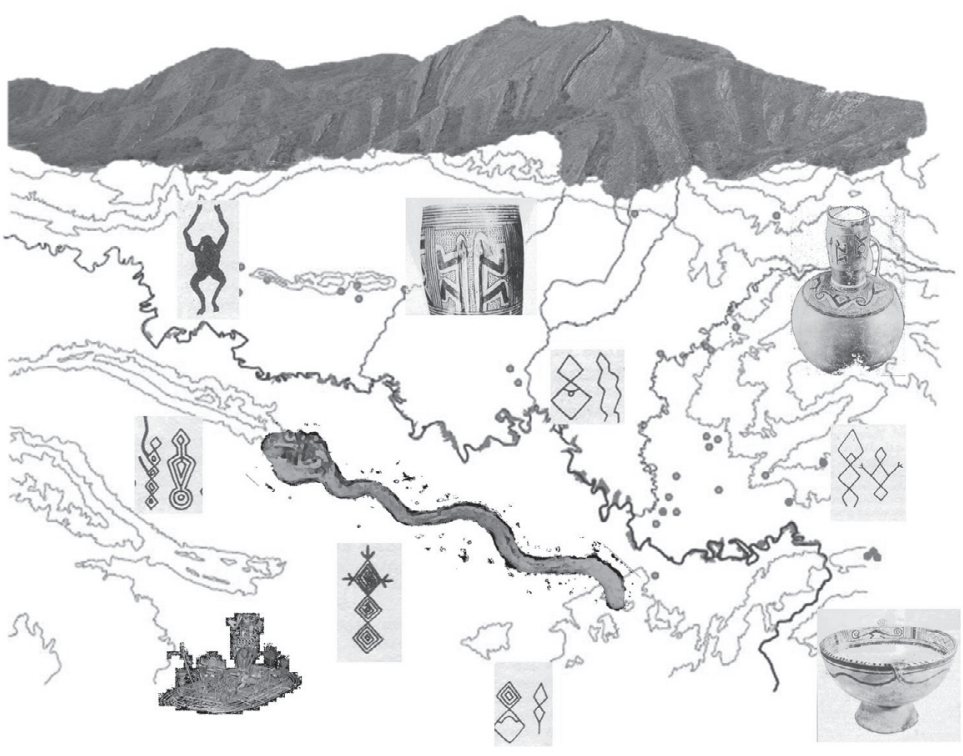

codificada de las leyes y la ignorancia en España sobre el Nuevo Mundo. Ello deriva en al menos dos obras que ayudarían a resolver estos vacíos y a la vez constituirían la base del ejercicio del cargo cosmógrafo-cronista: la Recopilación de leyes de Indias, una obra de Ovando, que se desarrolla de manera paralela al texto Ordenanzas del Consejo de Indias, iniciado por López de Velasco pocos años antes y en las cuales quedarían indicadas las funciones del nuevo cargo de cosmógrafocronista, y las Instrucciones a conquistadores y autoridades (o Título de las descripciones) que señalaban la metodología para compilar la información sobre el Nuevo Mundo (Portuondo, 2009).

Poco después de asumir la presidencia del Consejo de Indias, Juan de Ovando nombra a su protegido Juan López de Velasco como Cosmógrafo-Cronista Mayor en 1571. Aunque no poseía la formación en cosmografía, la cual se enseñaba en universidades como la de Salamanca desde la época medieval, poco a poco se amolda al cargo con el desarrollo de su primera obra Geografía y descripción universal de Indias, terminada en 1574, que incluía mapas, descripciones geográficas e hidrográficas y un cuadro sistemático de cada audiencia y provincia además de otros territorios notorios. Sus datos los obtuvo de los

(...) cuestionarios dirigidos a los oficiales de la iglesia, viejos documentos encontrados en las cámaras del Consejo, aquellos elaborados por Santa Cruz, los resultantes de sus requerimientos a las Indias en 1572, y un número de textos de autores privados
Fig. 1 Proceso de superposición de los elementos básicos para la construcción de una cartografía normativa actual, plano de Bogotá (E.A.A.B., c. 1954), aerofotografías del río Bogotá en 1949 (IGAC, vuelo C-25, S 2283) y creación en Autocad (2013) del lienzo geográfico del área de estudio.

3. El conjunto de estos documentos sería denominado Relaciones, a partir de la compilación efectuada por Marcos Jiménez de la Espada (1881-1895). Algunos autores han planteado subdividir esta categoría en varias más específicas, bien entre crónicas mayores y menores (Carbia, 1934), o bien entre cartas relatorias, relaciones y crónicas (Mignolo, 1982). 

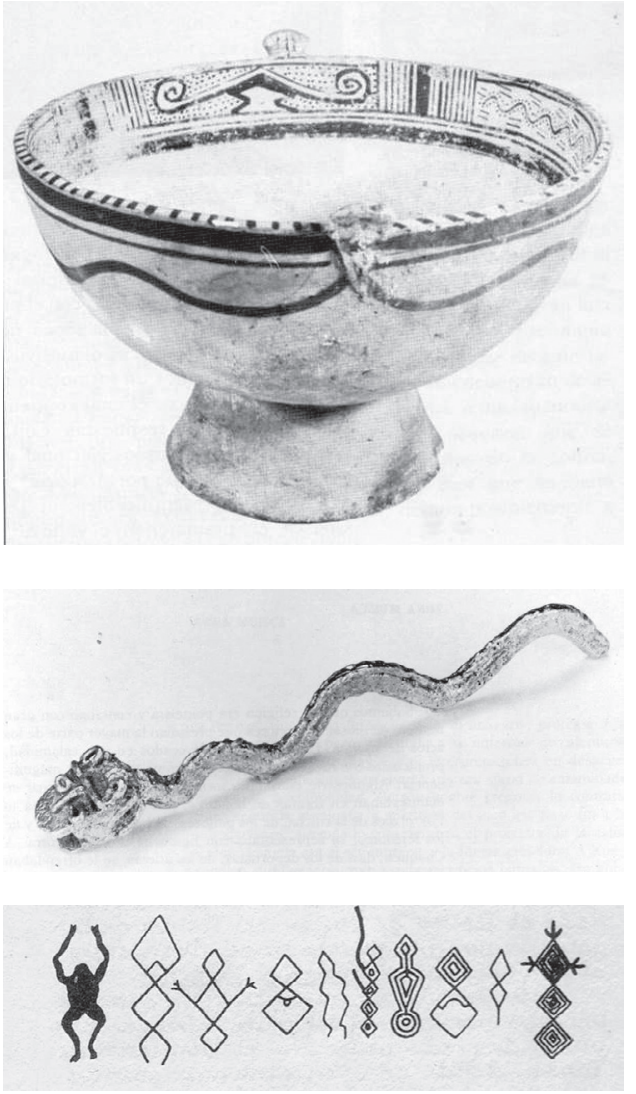

4. En la elaboración de mapas y las correcciones de cartas y prácticas de navegación se mantuvo el interés por desarrollar instrumentos de medición mediante los cuales se precisaran los fenómenos astronómicos. a los que pudo echarle mano (Portuondo, 2009, p. 172).

En 1591, con el retiro de Juan López de Velasco como cosmógrafo-cronista, se divide el cargo en dos de acuerdo con los lineamientos dados por Juan de Herrera, que favorecía una cosmografía más matemática ${ }^{4}$ y menos humanista, siguiendo de manera más estricta los lineamientos de Ptolomeo de racionalizar el mundo bajo los principios de la geometría de Euclides (Padrón, 2004). De esta manera, Arias de Loyola asume el oficio de Cronista Mayor, pero es reemplazado rapidamente por Antonio de Herrera y Tordesillas. Pedro Ambrosio Ondériz adopta el cargo de Cosmógrafo Mayor, pero también es sucedido poco después por Andrés García de Céspedes, que junto con Herrera y Tordesillas se convierten en los nuevos funcionarios en el Consejo de Indias. Así, las raíces del humanismo renacentista se verían cortadas y suplantadas por otra visión derivada de los procesos que condujeron a la revolución científica del XVIl. Es entonces cuando se pierde el fundamento integral de la geografía, cartografía, etnografía, historia natural e historia y algunos elementos de la astronomía, geología y meteo- rología que comportaba el saber cosmográfico (Padrón, 2004; Portuondo, 2009).

La producción de una cosmografía normativa

Los cuestionarios elaborados durante el periodo en que la cosmografía y la crónica se asumieron como un solo conocimiento fueron enviados a las Audiencias, Provincias y autoridades eclesiásticas, para ser respondidos por estas en 1569, 1573, 1577, 1584, 1592 y 1604. Al cuestionario de 17 preguntas formulado por Santa Cruz en 1546, en esa etapa todavía exploratoria del Nuevo Mundo, se sumaron otras tantas hasta alcanzar las 200 preguntas contenidas en un conjunto de 37 capítulos remitido por Ovando en 1569 (su estructura semejaba el cuestionario castellano del notario cuando efectuaba un interrogatorio), para recoger información sobre las poblaciones, divisiones administrativas y otros asuntos, a lo que siguió el conjunto de 135 preguntas dirigidas por él mismo a las autoridades eclesiásticas en 1570 (Cline, 1964).

A partir de estos primeros formularios López de Velasco elaboró su obra geográfica, en calidad del primer Cosmógrafo-Cronista Mayor, reutilizando algunas de las preguntas de los cuestionarios anteriores, entre estos los de 1569 y 1570. Él retomó y elaboró 50 preguntas para recoger información más precisa sobre lo ya establecido e incorporar a las nuevas poblaciones que se fueron asentando en el territorio en 1577, razón por la cual hizo más énfasis en la posición geográfica de las provincias que en su descripción. Se sabe que a los virreinatos del Perú y de la Nueva España envió 600 formularios para cada uno con el fin de que allí fueran diligenciados; mientras que a las Audiencias también les fueron remitidos los formularios, evidentemente se hizo en mucha menor cantidad, los formularios se enviaron junto con las Instrucciones como guía para ser respondidas por las autoridades locales, preferentemente los alcaldes mayores y los corregidores.

De acuerdo con Cline,

(...) las preguntas 1-10 aludían específicamente a poblaciones con habitantes españoles, de la 11 a la 15 se aplicaban particularmente a los pueblos de indios. Las preguntas $16-37$ se dirigían a las comunidades en el interior del territorio, 
escrutando tópicos más generales. Las preguntas 38-50 estaban diseñadas para recoger datos específicos de los puertos y otras poblaciones marítimas (Cline, 1964) ${ }^{5}$.

Las preguntas profundizan en aspectos como el medio ambiente y la toponimia, las ciudades y pueblos, las lenguas, la guerra, la historia, la demografía, la flora, los recursos minerales, las defensas, la vivienda y la vida económica. Al momento existen en total 200 cuestionarios respondidos ${ }^{6}$, los que según Portuondo y Cline, constituyen un rico material para indagar por la información etnográfica, económica y administrativa de los territorios en las Indias. A los cuestionarios se suman los mapas que acompañan estas descripciones, algunos dibujados bajo fuerte influencia amerindia (Mundy, 1996; Portuondo, 2009).

Los cuestionarios aquí mencionados fueron estudiados en extenso por Marcos Jiménez de la Espada (1881-1895) a finales del siglo XIX y solo después de mediados del siglo XX se reiniciaron las transcripciones de las relaciones de México (Acuña, 1982), Quito (Ponce 1992), Yucatán (de la Garza, 1983), Venezuela (Arellano, 1964) y Michoacán (del Paso y Troncoso, 1958). Cline elaboró un inventario de las respuestas remitidas desde Centroamérica. Para la Nueva Granada existen algunas cartas relatorias correspondientes a la primera mitad del siglo XVI (que no siguen un cuestionario específico), la más temprana hasta ahora transcrita data de 1539 (Tovar, 1995).

En cuanto a las relaciones, recientemente se ha propuesto asumir que el manuscrito conocido como el Epítome, y cuya autoría había sido atribuida a Gonzalo Jiménez de Quesada, fundador del Nuevo Reino de Granada, corresponde a un ejercicio realizado por Alonso de Santa Cruz de abreviar los largos textos que conformaban las respuestas a los cuestionarios y, con ello, de crear un atlas geográfico y cartográfico de consulta rápida (Millán, 2001). Esta labor emprendida por Santa Cruz nunca se llegó a cristalizar, López de Velasco tampoco lo pudo hacer.

La documentación producida con posterioridad a la creación del cargo de CosmógrafoCronista Mayor se condensa en la relación de la Audiencia del Nuevo Reino, en respuesta a los 37 capítulos elaborados por Ovando en 1569, el

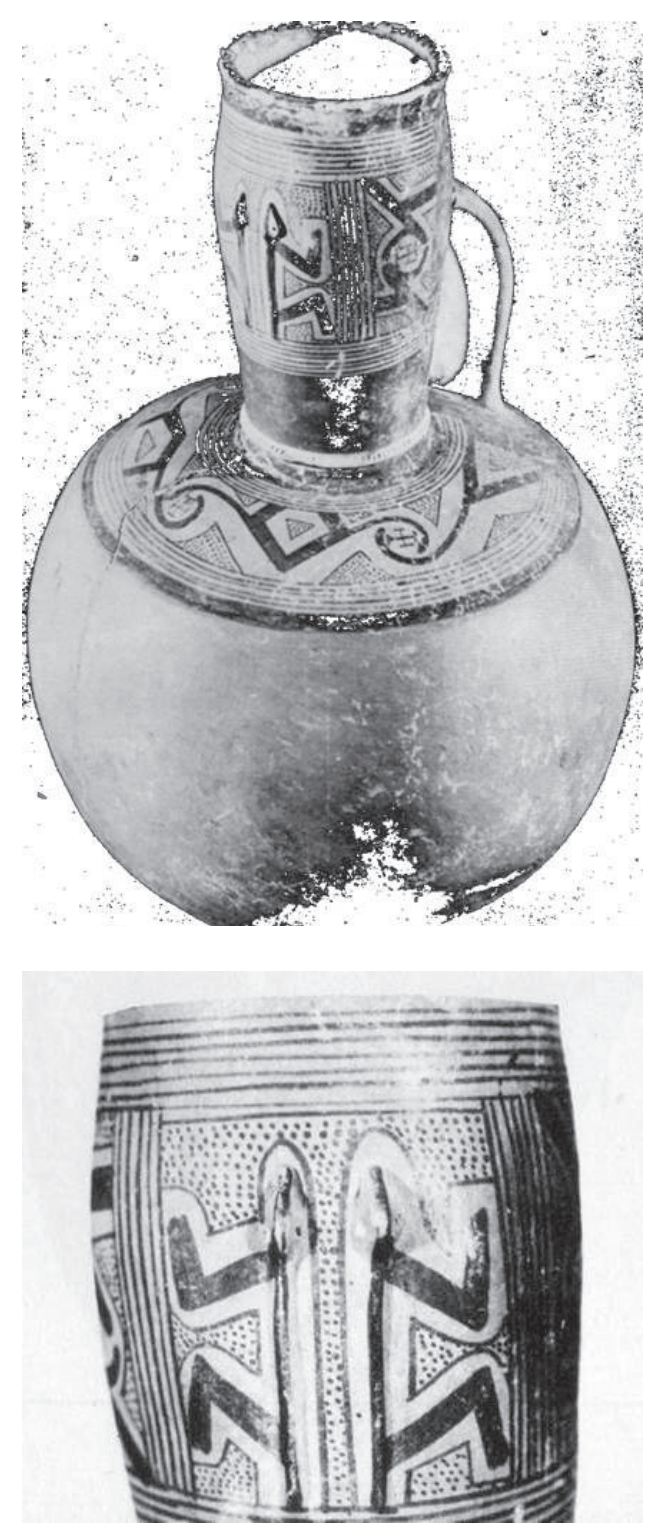

cual fue remitido desde Santa Fe en 1572 (Patiño, 1983; Tovar, 1995). Del trabajo realizado por Jiménez de la Espada fueron identificadas otras siete respuestas remitidas desde la Nueva Granada, entre 1580 y 1582, que cubren lugares andinos exclusivamente ${ }^{7}$ y que muy seguramente responden al cuestionario de López de Velasco. Asimismo, existe un mapa producido en 1584, en el que se plasma de manera muy genérica la ubicación de las ciudades, villas y pueblos de las jurisdicciones de Santa Fe y de Tunja; en general, fueron pocos los mapas remitidos desde el Nuevo Reino que situaron y representaron los elementos naturales y culturales de manera exacta ${ }^{8}$.

Después de la separación del cargo entre el cosmógrafo mayor y el cronista mayor, los cuestionarios se limitaron a hacer un reconocimiento sobre los recursos económicos, las comunicacio-
5. El artículo de Cline (1964) trae transcritas en el anexo las 50 preguntas.

6. Tanto Cline (1964) como Enrique Cañizares-Esguerra (2001), coinciden en llamar la atención sobre la afectación que tuvieron tanto la Leyenda Negra como el argumento de algunos académicos acerca del extremado utilitarismo desarrollado por los españoles frente a las políticas administrativas de sus colonias, por lo cual se argumenta que esto generó atrasos epistemológicos y metodológicos que permitieran al Consejo de Indias y al Cosmógrafo-Cronista asumir de manera científica la producción y el manejo de la información proveniente del Nuevo Mundo.

7. No obstante, Cline advierte que estos cuestionarios pueden estar entre Simancas, Madrid y Sevilla, o en Texas, lugares donde trasegaron estos documentos por múltiples motivos a partir de finales del siglo XVIII.

8. Para ahondar sobre el tema, ver por ejemplo Tovar (1993). 

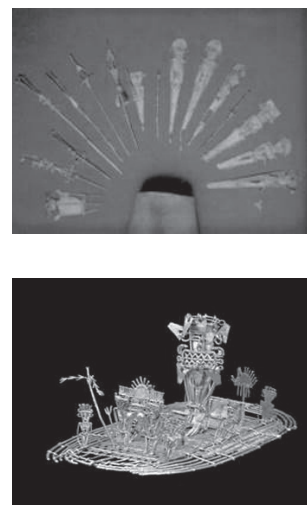

nes y la demografía en el nuevo territorio. Esto no solo contrasta con lo planteado anteriormente sino que también permite advertir el paulatino cambio que se produjo en la información que debía de recoger el cosmógrafo mayor. Se elaboró entonces el cuestionario compuesto por 355 preguntas, aparentemente organizado por el Conde Lemos, nuevo presidente del Consejo de Indias. De este nuevo formulario, remitido al Nuevo Mundo en 1604, se obtuvieron muy pocas respuestas, pero de ellas se han identificado 17 provenientes de Suramérica y entre estas, la de la Nueva Granada (Valencia, Paniagua, Fuente y Fuente, 2001; Tovar, 1995). A pesar del incremento en el número de las preguntas, la respuesta remitida desde la Audiencia de Santafé de Bogotá fue bastante resumida. Esto puede ser interpretado de dos maneras: que el cometido de Santa Cruz y López de Velasco de obtener documentos breves pero precisos se estaba cumpliendo, o que no existía el interés o no se le encargó a suficientes personas responder los cuestionarios.

Para López de Velasco fue de extrema importancia acompañar estas relaciones con mapas, por lo cual sus instrucciones se dirigían a obtener un producto más racional, guiado bajo reglas precisas que permitieran a dos personas distintas trazar una misma cartografía. Ello requería del uso de los principios de la geometría euclidiana y de la observación astronómica (más específicamente de los eclipses), con el objeto de realizar y plasmar las mediciones de latitud y longitud (Millán, 2001). Sin embargo, al analizar los mapas elaborados y remitidos desde los virreinatos y audiencias, es inevitable observar que las instrucciones para lograr este propósito no fueron tenidas en cuenta (Cline, 1964; Mundy, 1996; Padrón, 2004), más aún, hay quienes se niegan a asumirlos como mapas en realidad (Wood, 2010). Es por esto que se pone el énfasis en la inclinación inicial que tuvo la cosmografía hacia lo geográfico y lo corográfico y no tanto hacia el aspecto y la labor cartográfica.

Parte del problema ya esbozado se atribuye a la implementación del proceso, pues la labor de responder los cuestionarios estaba en manos de los habitantes de estos nuevos territorios: los españoles y los criollos educados y letrados. Es evidente que producir el texto escrito no representó para ellos dificultades y en la medida en que lograron familiarizarse con el entorno y describir aquello que les era desconocido (la vegetación, la fauna, las costumbres de los nativos, etc.), la tarea se les fue facilitando, pero obviamente se trataba de su versión de lo observado y por ello, también se muestra acorde con los intereses que los movía frente a la Corona. No obstante, aun cuando los asignados a responder el cuestionario fueran letrados, sus conocimientos de la geometría y de la astronomía no les alcanzaban para aplicar los principios establecidos en la ejecución de la cartografía que fundamentaba estas relaciones. En el Nuevo Mundo se favorecieron los principios de Strabo sobre los de Ptolomeo, como se evidencia en la documentación remitida desde Nueva España, en la que lo importante era dar cuenta de la autoría del documento, por lo que llevaba las firmas de sus ejecutores, mas no así el mapa cuya ejecución era encargada con frecuencia a los amerindios (Mundy, 1996) o a alguien ajeno a la producción del texto. De esta manera se forjó una realidad del Nuevo Mundo luego asumida como un hecho de verdad.

\section{La producción de una corografía interdisciplinaria de Bogotá}

Desde una aproximación interdisciplinaria actual, resulta interesante volver a examinar la cosmografía que data del siglo XVly comienzos del XVII, evaluar asimismo los documentos generados por los requerimientos del cargo de Cosmógrafo-Cronista Mayor; especialmente las respuestas a varios conjuntos de cuestionarios, pues estas permiten entender y confrontar las versiones dadas en ese entonces de la representación geográfica y corográfica del Nuevo Mundo, más específicamente desde la visión europea. Para el caso específico de la ciudad de Santafé y de los pueblos de indios de su entorno inmediato (hoy localidades conurbadas a Bogotá), se constituye tanto en un motivo de pesquisa como de contraste con los datos que brindan los estudios arqueológicos, históricos, ambientales y geológicos, entre otros, para interpretar las experiencias de quienes no respondieron los cuestionarios.

En 1954, Bogotá se conformó como Distrito Especial y con ello se anexaron los municipios de Bosa, Engativá, Fontibón, Suba, Usaquén y Usme. La resolución fue tomada al parecer, con resignación por la mayor parte de sus pobladores puesto que solo hubo algunas protestas en Fontibón. La escasa documentación y memoria sobre la historia de los asentamientos muiscas, los pueblos de indios coloniales y sus resguardos y los muni- 
cipios republicanos rápidamente fue englobada, absorbida y reemplazada por la historia de Santa Fe y la de sus habitantes españoles, teniendo como referente urbanístico lo que hoy constituye el Centro Histórico de La Candelaria y luego, en su condición más moderna, la Bogotá expandida.

El estudio que se adelanta busca reivindicar la trayectoria histórica de esas poblaciones, no solo para curar del olvido generado con el acto de anexión y las consecuencias que ha tenido en la configuración urbana, urbanística y administrativa, sino para entender cómo ha sido la ocupación humana y la transformación de este territorio. Más allá de las respuestas al cuestionario oficial se trata de analizar el uso social de los espacios teniendo en cuenta tres factores básicos para su comprensión: el medio natural, la cultura material y la sociedad.

Para cumplir con el propósito mencionado están los resultados de las investigaciones arqueológicas y entohistóricas, así como los estudios ambientales que permiten restituir ciertos aspectos de la vida de los asentamientos nativos antes y durante la conquista, a pesar de las múltiples intervenciones que han experimentado sus entornos hasta hoy. Un estudio en particular que explora estos aspectos y que proporciona algunos lineamientos para recrear el entorno natural y cultural del territorio que luego fuera colonizado, lo proporciona el proyecto desarrollado alrededor de la isla, reconocida en su época precolonial como Manahatta ${ }^{9}$.

Esta investigación parte de generar los datos suficientes (basado en cartografía antigua, fotos satelitales y resultados de análisis ecológicos e histórico-culturales de los lenape, indígenas que habitaron lo que hoy es Nueva York) para reconstruir el aspecto de la isla de Manhattan al momento de la llegada del capitán Henry Hudson y su tripulación en septiembre de 1609. Para ello, parte de la noción de paisaje ecológico entendido como

(...) un patrón particular de ecosistemas, su composición y organización que forman el hábitat para plantas y animales (...) y qué sucede cuándo las personas deciden que ya no necesitan un bosque o una quebrada y edifican talando el primero y desviando el segundo" (Sanderson, 2009, p. 25).

Lo que propone Sanderson es intentar identificar, bajo cada cuadra de la ciudad de Nueva
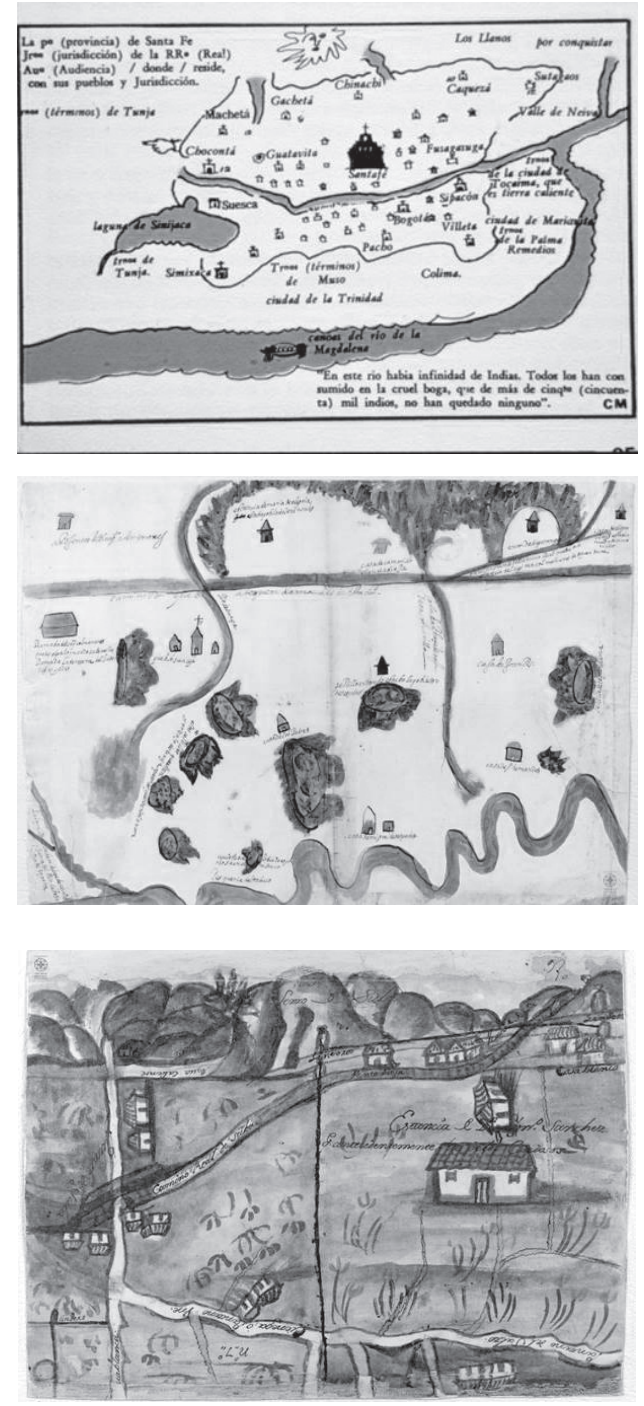

York, la no-vida geológica, topográfica, climática e hídrica y la exposición a catástrofes como inundaciones, incendios o heladas que podían alterar el curso de estos elementos. Paso seguido, Sanderson superpone a este mapa de la no-vida el de la vida, específicamente el de la ocupación de los grupos indígenas que habitaron el área al momento de la colonización; y por último, superpone a este paisaje aquel creado por los colonizadores y expresado en un mapa particular de Nueva York elaborado entre 1782-83 que detalla varios de los aspectos aquí señalados.

Para desarrollar un ejercicio semejante existen, para el área de Santafé y sus alrededores (en general para la Sabana de Bogotá), los estudios geológicos de suelos del Instituto Geográfico Agustín Codazzi (IGAC) (Botiva, 1988) ${ }^{10}$, los estudios de polen para conocer la vegetación endémica (Van der Hammen y González, 1963; Wijninga, 1996) y aquellos que versan sobre los cuerpos de
Fig. 2 Arriba.

Representación

cartográfica realizada por

Rodrigo Zapata en 1610

del pueblo y resguardo

de indios de Fontibón

(Archivo Histórico -

Universidad Javeriana).

Abajo. Reconstrucción

del pueblo de indios

de Fontibón basado en

fuentes documentales

(tomado de C. Peña,

2003, Reconstrucción

histórica y mapificación

del resguardo de

Fontibón 1593-1639,

Bogotá, Universidad

Nacional de Colombia).

Fig. 3 Representación cartográfica en la que se destaca los hitos geográficos como elementos de delimitación y localización del pueblo y las tierras de resguardo de los indios de Soacha y las estancias otorgadas a los españoles y sus descendientes en sus alrededores (AGN

Colombia, Mapoteca

4, Ref. 443 A, arriba y Ref. 444 A, abajo).

Fig. 4 Arriba. Raro ejemplar de la cartografía temprana realizada para la Provincia de Santa Fe (1584), la cual complementaba la información contenida en los cuestionarios de relación remitidos desde las colonias americanas al Cosmógrafo - Cronista Mayor (Museo de Bogotá 12971, reconstrucción del plano original elaborado por el arquitecto Carlos Martínez). Abajo.

Portada de las relaciones compiladas por el Cronista Mayor, Antonio de Herrera, en 1601.

9. Para más información sobre el tema ver http://welikia.org/.

10. Adicionalmente existen los estudios realizados por Pedro Botero, experto en suelos, en la investigación desarrollada en los predios de la Hacienda Terreros en inmediaciones de Soacha (arqueóloga Marcela Bernal, comunicación personal). 
Fig. 5 Fontibón -asentamiento muisca, pueblo de indios colonial, municipio republicanocelebra como propia la fundación de la ciudad española de Santa Fe de Bogotá (El Tiempo, agosto 6 de 2012, sección Hace 25 años).

Fig. 6 Representación iconográfica del ambiente anfibio ocupado por los muiscas expresada en su cultura material,

A. culebra (Museo

del Oro), B. batracios representados en el arte rupestre (M. Triana, 1972,

La civilización chibcha,

Cali, ed. Facsimilar

Carvajal \&t (ía), C. copa contenedora de bebidas

bordeada por culebras

(colección ICANH), D.

líder muisca posiblemente desplazándose en una balsa (Museo del Oro 011374B).

Fig. 7 A. Cartografía practicada basada en la signficación y uso del territorio muisca, B. flauta en hueso de ave s.i., C. moluscos, D. huesos de peces s.i. (tomados de B. Enciso, 1995, Ruinas de un poblado muisca en el valle del río Tunjuelito, Bogotá, Informe Instituto Colombiano de Antropología), E. imagen aumentada y detalle de semilla de Solanaceae (tomado de V.M. Wijninga, 1996, Paleobotany and Palynology of Neogene Sediments from the High Plain of Bogotá (Colombia). The Quaternary of Colombia, vol 21 (370 p.)).

Fig. 8 A. Cartografía practicada basada en los hitos del reordenamiento del territorio bajo nuevas significaciones del territorio, B. Plano del trazado de la vía Bogotá - Tunja (autopista norte) de 1805 , proyectado con la racionalidad costo-

beneficio y que atraviesa los humedales (Museo de Bogotá 12969), C. Cartografía practicada de Santa Fe en 1540 que resalta los puntos de confluencia y tensión entre los pobladores (véase Therrien, 2008).
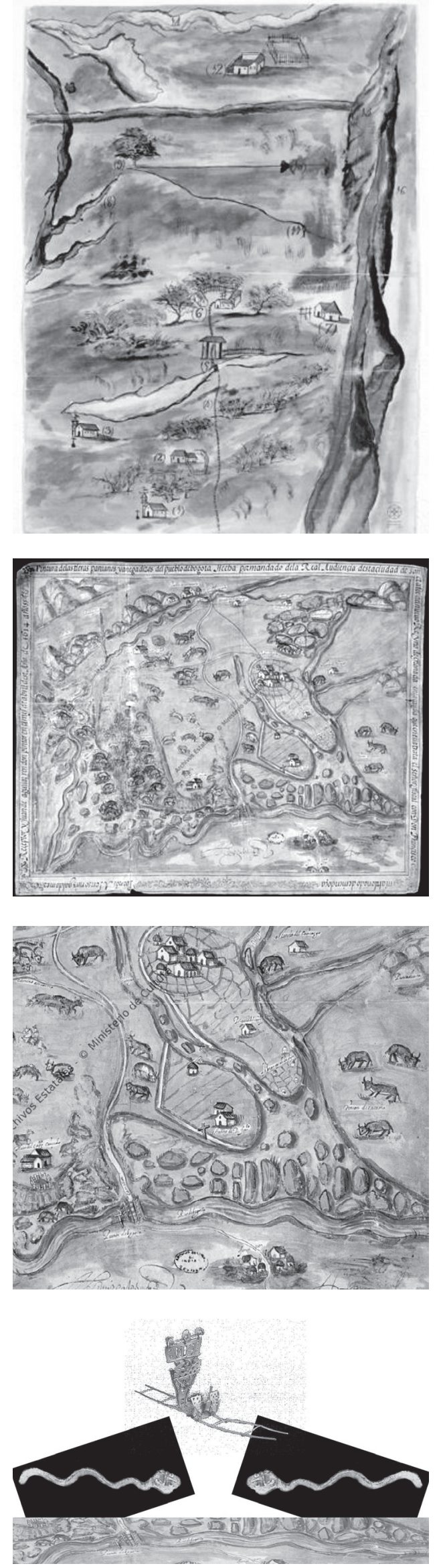

agua en Bogotá (E.A.A.B., 2003), entre otros, que permiten reconocer las condiciones ambientales al momento de la llegada de los españoles. De la misma manera, existen estudios arqueológicos, ya realizados y en curso, que permiten complementar esta visión ambiental con la cultural en un época previa a la conquista española. Entre ellos se destacan las investigaciones realizadas en los municipios de Fontibón, Funza, Suba y Tuna (Boada, 2006)'11, en los que es posible identificar las transformaciones efectuadas en el paisaje por los muiscas mediante las intervenciones en forma de camellones y canales de drenaje, una técnica desarrollada por los indígenas y aparentemente reutilizada por un tiempo por los españoles, con el fin de evitar y controlar las inundaciones ocasionadas por los ríos y los cuerpos de agua que abundaban en el entorno de lo que hoy es Bogotá. Asimismo, los estudios de polen y fitolitos complementarios a estas estructuras arqueológicas, han hecho posible identificar la flora natural y los cultivos desarrollados por los indígenas al momento de la conquista (Berrío, 2006).

En cuanto a la fauna, existen dos aproximaciones posibles para conocer los animales asociados a este entorno y a los muiscas. De un lado, se encuentran descripciones minuciosas de los animales presentes en la zona, como los de Cazucá, un sitio arqueológico situado hacia el suroccidente de la ciudad (Enciso, 1995), que ofrecen un rico y diverso espectro de ejemplares cuyos usos fueron mucho más amplios de lo reportado por los españoles: rituales, decorativos, utilitarios y comestibles (Enciso, 1996). Las evidencias de la fauna arqueológica se contrastan con otra fuente de información no tan convencional: los animales representados en los objetos arqueológicos, un análisis planteado por la bióloga Anne Legast (1996) en su examen de los artefactos en oro y cerámica en los que los muiscas plasmaron las representaciones de los animales de su universo mítico y del cotidiano.

A manera de complemento a los datos y fuentes ya mencionados, existen múltiples estudios arqueológicos adicionales que permiten recrear la configuración de los sitios correspondientes al período Muisca Tardío. La extensión de las áreas excavadas hace posible identificar las áreas de habitación, las distancias entre los bohíos, las rutas de tránsito y los entierros realizados por los indígenas. Con esto es posible establecer pautas de asentamiento y entender lo que representó el 
cambio introducido por el trazado de los pueblos de indios implantado por los españoles y el nuevo ordenamiento espacial que cambió los usos y significados del territorio.

Para la ciudad de Santafé, aunque no se cuentan con elementos en pie de la fundación original, lo cierto es que el seguimiento a la estratigrafía y la cronología de los materiales arqueológicos excavados en distintas edificaciones en La Candelaria (Therrien, Lobo Guerrero y Gaitán, 2002), junto con la revisión de fuentes documentales no convencionales, permite establecer que con toda seguridad se implantó el modelo ajedrezado, aunque su aspecto fue más alargado que la cuadrícula frecuentemente representada en los planos y donde los ríos jugaron el papel de elementos estructurantes (Therrien, 2008), lo que difiere de los planos y reconstrucciones históricas hechas sobre la ciudad que la recrean como una cuadrícula perfecta, delimitada por sus dos ríos principales (Martínez, 1988; Mejía, 2012).

En sintesis, desde la mirada de la arqueología y de la etnohistoria, con el uso de fuentes de información alternas y poco reconocidas que sus métodos brindan, particularmente los arqueológicos, se configura un primer referente de ideas que permiten cuestionar el conocimiento legitimado y aceptado de lo que se sabe sobre la ciudad colonial y los pueblos de indios (Therrien y Jaramillo, 2004), que deriva de la representación por cuestionario de la cosmografía y corografía normativa.

Como bien lo señala Kagan, se trata de construir la representación comunicéntrica, en la que se

(...) sustituyen los componentes físicos de la ciudad, la urbs, por su lado humano, la civitas (...) la idea de la ciudad como una comunidad con un carácter especial, distintivo, en conjunto con las memorias y tradiciones que sirvieron para diferenciar una comunidad de otra (Kagan, 2000, pp. $16-17)^{12}$.

\section{Corografías y cartografías}

practicadas: la otras voces de las representaciones comunicéntricas

Aunque los cronistas coloniales argüían que solo habiendo pisado la tierra americana era posible elaborar una relación de las audiencias y provin-
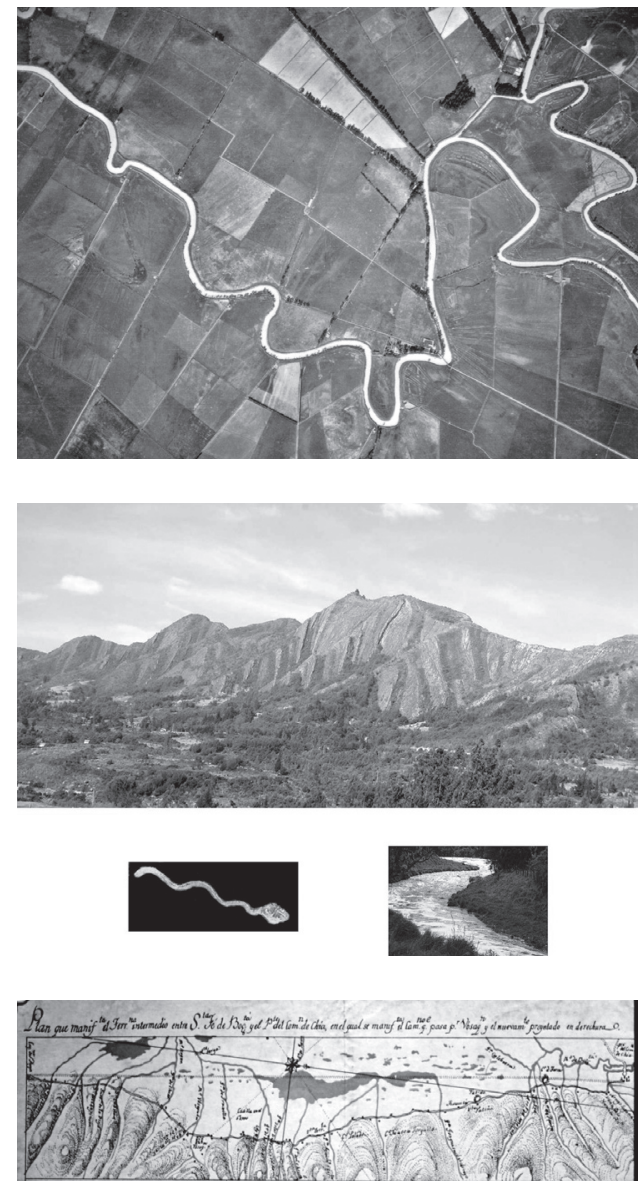

cias, pronto sus testimonios también se vieron desbordados por la tarea de asumir descripciones de territorios y poblaciones que nunca habían llegado a conocer, dependiendo para ello de lo que otros relataban (Kohut, 2007). Es decir, no solo se trata de la versión propia de los españoles intentando presentar a Europa ese nuevo mundo, sino de interpretar y traducir lo que otros habían visto. Pero además, esto debía demostrar cuán efectivos o no fueron los mandatos reales, las ordenanzas $\mathrm{y}$ todos los instrumentos normativos que se desarrollaron para crear un dominio perfecto, por lo cual el resultado del ejercicio realizado por el cosmógrafo-cronista mayor llevó a que se ajustaran a su ideal y lenguaje.
11. Además del estudio de Boada, Patrones de asentamiento regional y sistemas de agricultura intensiva en Funza y Fontibón, Sabana de Bogotá (Colombia) que todavía está en desarrollo.

12. La distinción entre corográfico y comunicéntrico según Kagan (2000), deriva de la acepción que se puede tener de la ciudad, pues siguiendo a Covarrubias, esta puede ser tanto civitas (un conjunto de ciudadanos que se han congregado para vivir juntos bajo las mismas leyes y gobierno), como urbs (en tanto las edificaciones, lo construido) (Covarrubias, 1611). 
De esta manera, se propuso cartográficamente a las montañas y ríos como límites de territorios o en conjunto con los caminos, se convertían en vías de comunicación, mientras se representaban las ciudades de españoles separadas y diferenciadas de los pueblos de indios (la república de españoles y la república de indios). Las descripciones geográficas narraban el paso por esos hitos límites o de comunicación, a la vez que las corografías detallaban insistentemente las costumbres de unos grupos humanos, pero de la manera como eran antes de confluir y generar procesos de transculturación, en el sentido dado por Pratt (1992). Estos relatos se convirtieron en fórmulas convencionales para reiterar las ideas normativas emanadas de la Corona Española. Como lo señala Wood,

(...)los mapas no se fundaron en un instinto primario "para comunicar un sentido de lugar, algún sentido de aquí en relación con allá', sino en la necesidad de los nacientes Estados de dar forma y organizar sus muchos intereses... no son representaciones sino sistemas de proposiciones, argumentos sobre lo que podría ser el mundo (Wood, 2010, p. 8).

La corografía y cartografía practicada parte de la idea de la representación comunicéntrica que pretende ir más allá de esa relación por cuestionario, fundamentándose en fuentes de distintas disciplinas y evidencias que dan cuenta de cómo se usó y qué significó el territorio, sus elementos geográficos y naturales, de cómo se vivió el día a día en los pueblos y la ciudad, tomándolos como experiencias de los individuos de diferentes orígenes que confluyeron en un mismo espacio. Más importante aún, sin asumir las formas de vinculación entre amerindios, españoles, criollos y africanos, como la aproximación entre unidades culturales discretas, pues las fuentes arqueológicas y etnohistóricas indican tramas más complejas desarrolladas en las relaciones entre unos y otros para sobrevivir en una sociedad en continua configuración.

Para el caso de la jurisdicción de Santafé de Bogotá, la representación normativa en la cartografía es escasa. Al igual que las descripciones geográficas y corográficas, plantea un ejercicio de contra-mapeo,
(...) enraizado en las prácticas del arte de mapear de principios del siglo XX, en el movimiento de los mapas mentales de los 60 , en el mapeo indígena y biorregional y la cartografía crítica, con todas las fusiones, las mezclas y los cruces de fronteras, y propulsado por la injusticia global (Wood, 2010, p. 111).

El ejercicio efectuado hasta el momento, desde las fuentes arqueológicas y entohistóricas, muestran la estrecha relación que prefirieron guardar los muiscas con el río Bogotá y con otros de relativa importancia en la zona, como los ríos Tunjuelito y Juan Amarillo, al establecer sus asentamientos permanentes cerca a estos cuerpos de agua. Uno de los cambios de mayor impacto para la población nativa causado por los españoles, fue el de escoger las faldas de las cordilleras como sitio de asentamiento de la ciudad, dándole la espalda a estas fuentes de vida del territorio. Esa condición conllevó, entre otras, a cambiar el significado de Fontibón como sitio ceremonial (Langebaek, 1986; Londoño, 1986) y centro astronómico, en lo que hoy constituye el humedal de Jaboque (Marriner, 2003), donde el jefe religioso muisca realizaba sus rituales para controlar un medio considerado inhóspito como el de este sector. La mirada se gira hacia los cerros, en el lado opuesto, coronados desde el siglo XVIl con una capilla en su punto más elevado: Monserrate. Este es un cambio en su forma de percibir y vivir el espacio que ha sido detonante de muchos de los problemas que hoy vuelven a surgir, cuando el río anega de manera repetida y constante las partes más bajas de Bogotá, las cuales los muiscas tenían controladas mediante su sistema de camellones y canales y la celebración de sus ritos.

lgualmente, se ha incorporado información sobre las condiciones del ambiente natural del área estudiada para reconocer las distancias existentes entre los poblados indígenas, definir las características de los sitios de emplazamiento y a la vez, tener en cuenta las zonas de amortiguamiento entre unas y otras y la función atribuida a ellas (generalmente de ritual o de reserva). También se han introducido los datos de la localización de los recursos básicos, a lo que habría que agregar los recorridos entre un punto y otro, cómo se conectaban y comunicaban. Todo ello para ir entendiendo con más claridad cuál fue el impacto ocasionado por la colonización: 
(...) estando a la puerta de la Iglesia después de misa// en presencia del padre fray [Gerónimo de Chaves] guardián y cura de// este dicho pueblo (Soacha) de don Juan Tinjo y don Juan [ilegible] capitanes// y muchos indios el dicho corregidor leyó este dicho mandamiento y por // Iengua de Francisco dio a entender lo contenido (...) // (los indios) dijeron que las tierras que // se piden por Antonio Jacinto de Guevara no son suyas y estamos // fuera de su resguardo y que (...) // les dejen libres los caminos por don//de sacan leña para el servicio de su pueblo ${ }^{13}$.

Esta perspectiva alternativa sobre la sociedad colonial emergente, visto desde el pueblo de indios de Tunjuelo, en la que de manera violenta o sutil se produjeron las transformaciones y creaciones en el nuevo orden social, plantea observar desde las actividades rutinarias (la mirada corográfica) cómo se producían los cambios en las comunidades amerindias y cuestiona las situaciones que se deducen directamente del análisis del rígido orden social representado en la relación por cuestionario. Es el caso de Tunjuelo, donde encomenderos y estancieros acudían a misa en la iglesia de este pueblo (y no a las de Santafé), evidentemente sin tomar el camino real ni mantener la división de las repúblicas promulgada. Rutas y conexiones que no se registran, como tampoco las alianzas. Allí, a raíz de un terremoto en 1643 , se dispone la reconstrucción del templo del pueblo de indios manconumadamente:

Memoria de los vecinos y parroquianos españoles// de la iglesia de Tunjuelo y lo que cada vecino ofrece// a Dios y a su majestad para ayuda de su re[e]dificación// (...) Parroquianos de Santa Bárbara que tienen sus estancias del río de// Fucha hacia Tunjuelo y que en creciendo el río se les administraba//con más comodidad (...) [y los indios] Don Juan cacique mandó cuatro pesos (4)// Andrés Pérez mandó seis patacones (6)// Luis [difuminado] mandó dos pesos (2)// Pedro [Guiamachagua] mandó tres patacones (3)// Juan Matamoros mandó tres patacones (3)// Luis Ortega mandó un patacón (1)// Alonso Criollo ${ }^{14}$.
En la misma ciudad, aquella representación de Santafé como espacios y lugares donde confluían los españoles para afianzar y reproducir sus costumbres, en iglesias, edificios institucionales y plazas, el contra-mapeo resulta en un registro de escenarios múltiples, donde comerciantes e indígenas se convierten en el principal sostén de la ciudad (Therrien y Jaramillo, 2004; Therrien, 2008). La cartografía y corografía practicada plantea dar cuenta de la adecuación del entorno para adaptarse a los distintos modelos de ocupación, tiempo y distancia, las variaciones en la composición demográfica, las conexiones entre sí y las relaciones de dependencia o dominación, y a situar los innumerables conflictos en la reestructuración social y jerárquica que afectaron la configuración de la ciudad de Santafé y también a las poblaciones de su entorno inmediato.

\section{Referencias}

Acuña, R. (Ed.) (1982). Relaciones geográficas de Indias, México: Universidad Nacional Autónoma de México.

Arellano, A. (Ed.) (1964). Relaciones geográficas de Venezuela. Caracas: Academia Nacional de Historia.

Berrío, J. C. (2006). Análisis de polen de los camellones de Guaymaral y la Filomena, Suba. En A. M. Boada. Patrones de asentamiento regional y sistemas de agricultura intensivo en Cota y Suba, Sabana de Bogotá (Colombia) (pp. 109-131), Bogotá: Fundación de Investigaciones Arqueológicas Nacionales.

Boada, A. M. (2006). Patrones de asentamiento regional y sistemas de agricultura intensivo en Cota y Suba, Sabana de Bogotá (Colombia), Bogotá: Fundación de Investigaciones Arqueológicas Nacionales.

Botiva, Á. (1988). Pérdida y rescate del patrimonio arqueológico nacional. Arqueología Revista de estudiantes de Antropología, 5 (2), 3-36.

Carbia, R. (1934). La crónica oficial de las Indias Occidentales: Estudio histórico acerca de la historiografía mayor de hispanoamérica en los siglos XVI a XVIIl. La Plata: Universidad Nacional de La Plata (UNLP) - FAHCE.

Cañizares-Esguerra, E. (2001). How to Write the History of the New World, Stanford: Stanford University Press.

Cline, H. (1964, agosto). The Relaciones Geográficas of the Spanish Indies, 1577-1586,
13. AGN, Fondo Miscelánea, Tomo/Rollo: 114, No. Orden: 14, ff: 75-77, 1621.

14. AGN, Fábrica de Iglesias, SC.26,12,D.2, Microfilm 012/21, ff. 36 r-52 v, 1644. 
Hispanic American Historical Review, (44), 341-374.

Covarrubias, S. de (1611). Tesoro de la lengua castellana. Recuperado de: http://fondosdigitales.us.es/fondos/libros/765/614/tesorode-la-lengua-castellana-o-espanola/

De la Garza, Mercedes (Ed.) (1983). Relaciones geográficas de la gobernación de Yucatán, México: UNAM.

Del Paso y Troncoso, F. (Eds.) (1958). Relaciones geográficas de la Diócesis de Michoacán. Guadalajara.

E.A.A.B. (Empresa de Acueducto y Alcantarillado de Bogotá) (2003). Historia del agua en Bogotá. Bogotá, 1968; E.A.A.B. El agua en la historia de Bogotá, 1538-1937. Bogotá: Villegas editores.

Enciso, B. (1995). Ruinas de un poblado muisca en el valle del río Tunjuelito. Informe final. Bogotá: Instituto Colombiano de Antropología ICAN (hoy ICANH) - COLCULTURA.

Enciso, B. (1996) Fauna asociada a tres asentamientos muiscas del sur de la Sabana de Bogotá, siglos VIIl al XVI. En B. Enciso y M. Therrien (Eds.) Bioantropología de la Sabana de Bogotá, siglos VIII al XVI DC. (pp. 41-58). Bogotá: ICAN.

Jiménez de la Espada, Marcos (1881-1895) Relaciones geográficas de Indias, 45 v., Madrid: Academia de Historia.

Kagan, R. (2000) Urban Images of the Hispanic World, 1493-1793. New Haven: Yale University Press.

Kohut, K. (Ed.) (2007). Introducción, Las crónicas de Indias y la teoría historiográfica: desde los comienzos hasta mediados del siglo XVI. En Narración y reflexión: crónicas de Indias y la teoría historiográfica (pp. 15-60). México, D.F.: El Colegio de México.

Langebaek, C. (1986) Las ofrendas en los Andes septentrionales de influencia chibcha, Boletín del Museo del Oro, (16), 40-47.

Legast, A. (1996). El animal en la sociedad muisca. En B. Enciso y M. Therrien (Eds.) Bioantropología de la Sabana de Bogotá, siglos VIIl al XVI DC. (pp. 21-40). Bogotá: ICAN.

Londoño, E. (1986). Un mensaje del tiempo de los muiscas, Boletín del Museo del Oro, (16), 48-57.

Marriner, H. (2003). Solstice and Scorpius Alignments of the Jaboque Petroform Menhirs. Bogotá: Gipri. Informe no publicado.
Martínez, C. (1988). Santafé. Capital del Nuevo Reino de Granada, Bogotá: Banco Popular.

Mejía, G. (2012) La ciudad de los conquistadores. Bogotá: Editorial Pontificia Universidad Javeriana.

Mignolo, W. (1982). Cartas, crónicas y relaciones. En L. Iñigo Madrigal (Ed). Historia de la literatura hispanoamericana (pp. 57-116). Madrid: Cátedra.

Mignolo, W. (1995). The Darker Side of the Renaissance. Ann Arbor: University of Michigan Press.

Millán, C. (2001). Epítome de la conquista del Nuevo Reino de Granada: La cosmografía española del siglo XVl y el conocimiento por cuestionario. Bogotá: CEJA.

Mundy, B. (1996). The Mapping of New Spain: Indigenous Cartography and the Maps of the Relaciones Geográficas. Chicago: University of Chicago Press.

Padrón, R. (2004). The Spacious Word. Cartography, Literature, and Empire in Early Modern Spain. Chicago: The University of Chicago Press.

Patiño, V. M. (1983). Relaciones geográficas de la Nueva Granada (siglos XVI a XIX). Cespedesia (45-46), 113-137.

Pratt, M. L. (1992). Imperial Eyes. Travel Writing and Transculturation. Londres: Routledge.

Ponce, P. (Ed.) (1992). Relaciones histórico-geográficas de la Audiencia de Quito, siglos XVI-XIX. Madrid: Consejo Superior de Investigaciones Científicas (CSIC).

Portuondo, M. M. (2009). Secret Science. Spanish Cosmography and the New World. Chicago: University of Chicago Press.

Sanderson, E. (2009). Manahatta: A Natural History of New York City. Nueva York: Abrams.

Solano, F. (Ed.) (1988). Cuestionarios para la formación de las Relaciones Geográficas de Indias, siglos XVI / XIX. Madrid: CSIC.

Therrien, M. (2008). Indigenas y mercaderes: Agentes en la consolidación de facciones en la ciudad de Santafé. En J. Gamboa (Comp.) Los muiscas en los siglos XVI y XVII: Miradas desde la arqueología, la antropología y la historia (pp. 169-210). Bogotá: Universidad de los Andes - CESO.

Therrien, M. y Jaramillo L. (2004). “Mi casa no es tu casa”. Procesos de diferenciación social en Santafé, siglos XVl y XVIl. Bogotá: Instituto Distrital de Cultura y Turismo. 
Therrien, M, Lobo Guerrero, J.y Gaitán, F. (2002). Cultura material y ciudad. Civilidad y policía en la Santafé colonial, siglos XVI y XVII. Informe final. Bogotá: Fundación de lnvestigaciones Arqueológicas Nacionales (FIAN).

Tovar, H. (1993). Relaciones y visitas a los Andes. Siglo XVI. Tomo l. Bogotá: Colcultura - Instituto Colombiano de Cultura Hispánica.

Tovar, H. (1995). Relaciones y visitas a los Andes. Siglo XVI. Tomo 111. Bogotá: Colcultura Instituto Colombiano de Cultura Hispánica.

Valencia, P., Paniagua, J., Fuente, F. J. y Fuente, J. (2001). Relaciones de Indias: Nueva Granada y
Virreinato de Perú, vol. 5. León: Universidad de León.

Van der Hammen, T. y González, E. (1963). Historia del clima y la vegetación del pleistoceno superior y del holoceno de la sabana de Bogotá. Boletín de Geología, (11), 189-266.

Wijninga, V. (1996). Paleobotany and Palynology of Neogene Sediments from the High Plain of Bogotá (Colombia). Evolution of the Andean Flora from a Paleoecological Perspective. The Quaternary of Colombia, 21.

Wood, D. (2010). Rethinking the Power of Maps. Nueva York: The Guilford Press.

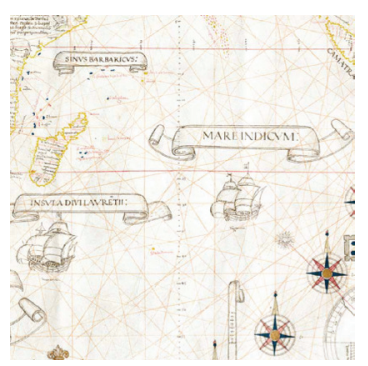

